\title{
Dosing Considerations for Antibodies Against COVID-19
}

\author{
Million A. Tegenge ${ }^{1} \cdot$ Iftekhar Mahmood $^{2} \cdot$ Evi Struble $^{3} \cdot$ Basil Golding $^{3}$
}

Accepted: 17 November 2020 / Published online: 1 December 2020

(c) The Author(s) 2020

\begin{abstract}
At present, no cure is available for COVID-19 but vaccines, antiviral drugs, immunoglobulins, or the combination of immunoglobulins with antiviral drugs have been suggested and are in clinical trials. The purpose of this paper is to discuss the role of a pharmacokinetic and viral load analysis as a basis for adjusting immunoglobulin dosing to treat COVID-19. We reviewed the pre-clinical and clinical literature that describes the impact of a high antigen load on pharmacokinetic data following antibody treatment. Representative examples are provided to illustrate the effect of high viral and tumor loads on antibody clearance. We then highlight the implications of these factors for facilitating the development and dosing of hyperimmune anti-SARS CoV2 immunoglobulin. Both nonclinical and clinical examples indicate that high antigen loads, whether they be viral, bacterial, or tumoral in origin, result in increased clearance and decreased area under the curve and half-life of antibodies. A dosing strategy that matches the antigen load can be achieved by giving initially high doses and adjusting the frequency of dosing intervals based on pharmacokinetic parameters. We suggest that study design and dose selection for immunoglobulin products for the treatment of COVID-19 require special considerations such as viral load, antibody-virus interaction, and dosing adjustment based on the pharmacokinetics of the antibody.
\end{abstract}

\section{Introduction}

Coronavirus disease 2019 (COVID-19) is an infectious disease caused by a novel strain of a family of viruses responsible for illnesses from the common cold to severe acute respiratory syndrome (SARS). Known as SARS coronavirus 2 (SARS-CoV-2), it was first discovered in December 2019 in Wuhan, China, and since then has spread all over the world. In March 2020, the World Health Organization declared the

Disclaimer: These findings are an informal communication and represent the authors' best judgment. These comments do not bind or obligate the US Food and Drug Administration.

Basil Golding

Basil.Golding@fda.hhs.gov

1 Division of Clinical Evaluation and Pharmacology/ Toxicology, Office of Tissue and Advanced Therapies, Center for Biologics Evaluation and Research, US Food and Drug Administration, Silver Spring, MD, USA

2 Mahmood Clinical Pharmacology Consultancy LLC, Rockville, MD, USA

3 Division of Plasma Protein Therapeutics, Office of Tissue and Advanced Therapies, Center for Biologics Evaluation and Research, US Food and Drug Administration, 10903 New Hampshire Avenue, Silver Spring, MD 20993-0002, USA

\section{Key Points}

This review provides an overview of dosing strategies for anti-SARS CoV-2 antibody products based on PK and viral load analysis.

Study design and dose selection for antiviral antibody products requires special attention to viral load, antibody-virus interaction, and antibody pharmacokinetics.

COVID-19 outbreak a pandemic. As of 2 November, 2020, more than 45 million cases were reported across the world with more than 1.2 million deaths.

An estimated $40 \%$ of individuals infected with SARSCoV-2 do not develop symptoms [1]. Those who do, start to exhibit signs and symptoms of COVID-19 2-14 days after exposure. The time after exposure and before having symptoms is called the incubation period, during which a presymptomatic spread takes place [3]. The signs and symptoms range from mild to severe and include fever, cough, fatigue, chills, sore throat, loss of smell and taste, and the most serious condition of SARS [2,3].

At present, there is no cure for COVID-19, although some treatments, such as remdesivir [4], convalescent plasma [5], 
steroids [6], interleukin-6 inhibitors including monoclonal antibodies (mAbs), antiviral drugs, immunoglobulin (IG), or the combination of IG with antiviral drugs have been suggested and are in clinical trials. The development of any drug for the cure or management of a disease is a deliberate and lengthy process. In the case of COVID-19, scientists have a heightened sense of urgency to discover safe and effective treatments for its management and cure. It should be recognized that where the drug development process is complex, a thoughtful scientific approach can help optimize the effort, cost, and time to a successful outcome. In this article, we describe several factors that should be considered for antibody drug development and suggest effective dosing strategies for human anti-SARS-CoV-2 IG (hCoV2IG) products. In this regard, we reviewed relevant published studies and publicly available regulatory documents on the pharmacokinetics (PK) and pharmacodynamics and dosing of polyclonal and $\mathrm{mAb}$ products.

\section{Special Clinical Pharmacology-Related Factors for Dosing Considerations of Antiviral Antibody Products}

\subsection{Viral Load}

A discussion of viral load is relevant here because the dose of antibody required for treatment is a function of the viral load (see below). In COVID-19, there is little or no viremia, thus the total viral load can only be assessed by sampling the viral load in various mucosal surfaces.

The assays for viral load measurement need to be quantitative. They consist of the "gold standard", the plaque assay, and the quantitative real-time polymerase chain reaction (PCR) assay. The latter measures a cycle threshold (Ct) value, which refers to the PCR cycle, resulting in amounts of amplified DNA that surpass a pre-defined threshold. Thus, $\mathrm{Ct}$ values are inversely related to the viral RNA copy number $[7,8]$.

Several studies have been performed in an attempt to correlate viral load and disease severity [7,9-11]. Higher viral loads have been associated with more severe disease.

Zheng et al. [9] evaluated viral loads at different stages of disease progression in patients infected with SARS-CoV-2 during the first 4 months of the epidemic in Zhejiang Province, China. There were 96 patients with confirmed SARSCoV-2 with 22 patients with mild symptoms and 74 with severe symptoms. A higher viral load and a later shedding peak were noted in patients with severe disease than in patients with mild disease.

In another report, a higher viral load for SARS-COV-2 significantly correlated with higher mortality [7]. In this study, viral titers from nasopharyngeal swabs of a cohort of
1145 hospitalized patients and a positive SARS-CoV-2 diagnostic test were re-evaluated using a real-time quantitative PCR. Even after adjusting for multiple co-morbidities and other factors (such as sex and age), a significant independent association was seen between viral load and mortality. In yet another study, mortality in 3014 hospitalized patients was higher for subjects with a high viral load (lower $\mathrm{Ct}$ value) measured at admission using a nasopharyngeal swab [11].

Given the novelty of the SARS-CoV-2 virus and the nature of the infection, challenges in incorporating viral load measurement in clinical trials abound. There are, currently, no national or international plaque or quantitative PCR assays or assay reagents to assess viral load. Clinical and academic laboratories are developing their own tests [7] but a lack of standard reagents (such as primers and controls) can complicate combining or even comparing data across multiple sites or laboratories. We do not know yet how viral titers from different collection sites correlate with each other and with disease progression/severity and whether reductions in viral loads in the nasal mucosa, oropharyngeal swabs, lower respiratory samples, the sputum, or elsewhere are those we need to measure or monitor. Despite the controversy, the detection of viral load early or during the disease, using best available quantitative and diagnostic tests, may provide a useful guide for the appropriate dosing selection of antibodies for COVID-19. Detection of viral load can be used as a marker for the severity of viral disease and measurement of treatment efficacy for mAbs and polyclonal antibodies. Finally, the viral load can be used as a stratification tool in analyzing early-stage clinical trial data and to identify individuals most likely to benefit from treatment in any subsequent trials.

\subsection{Drug-Virus Interaction}

An appropriate initial dosing of an antibody to manage or cure a viral disease is of critical importance. The efficacious dose is dependent on the viral load. This is because antiviral agents that bind the virus are cleared more rapidly from the body as a function of the viral load. The relationship between antibody levels and viral load can be nonlinear and can be described using the concept of target-mediated drug disposition [12]. For example, in the presence of hepatitis $\mathrm{B}$ virus (HBV), an IG drug binds to the virus resulting in its rapid elimination. As the viral load decreases, the elimination rate of the product slows down [13]. Such clinical examples of the interplay between pharmacodynamic and pharmacokinetic parameters of IG are discussed in more detail in the next section. A few examples from nonclinical studies are described as follows.

Anthrasil ${ }^{\circledR}$, a polyclonal IG derived from healthy vaccinated donors was approved by the US Food and Drug Administration, using the Animal Rule, for the treatment 
of anthrax disease following inhalation of Bacillus anthracis spores. When administered to rabbits challenged with anthrax spores, Anthrasil ${ }^{\circledR}$ exhibited a two-fold higher clearance than in healthy animals [14]. The same was not seen in challenged cynomolgus macaques, but a larger genetic variability characteristic of primate species may have confounded the results. Another anti-anthrax product, the monoclonal IG, obiltoxaximab, had a similar doubling of the clearance in rabbits and monkeys challenged with anthrax spores as compared to non-infected animals [15]. Furthermore, a mAb against Staphylococcus aureus exhibited an increased clearance and decreased half-life in infected mice vs those without infection [16].

As is the case for all therapeutics, the efficacy of antiviral antibody preparations is related to the dosing levels and regimen. For example, when tested in animals, palivizumab $\left(\right.$ Synagis $\left.^{\circledR}\right)$, a mAb indicated for the prevention of serious lower respiratory tract disease caused by respiratory syncytial virus in high-risk children, showed a dose-response reduction in viral titers in the lung [17]. Safety and efficacy clinical trials confirmed the highest dose was the efficacious dose, ultimately resulting in regulatory approval for respiratory syncytial virus prophylaxis [18]. The same dose-effect relationship is becoming evident as clinical and preclinical data from the current epidemic become available. Recently, 2807 patients with COVID-19 transfused with SARS-CoV-2 convalescent plasma exhibited a statistically significant gradient of mortality in relation to antibody levels, with those receiving units with higher antibody levels having lower 7- and 30-day mortality [19]. Finally, potent mAbs isolated from SARS-CoV-2 convalescent donors, such as $\mathrm{mAb}$ CC12.1, exhibited a dose-related effect in challenged animals, as evidenced by less weight loss and smaller viral load in the lung at the highest doses [20]. Other anti-SARSCoV-2 mAbs have been tested in animals and are being proposed as potential therapies for COVID-19 [21].

These observations are important for initial dosing and subsequent dose adjustment. In other words, initially a high or repeated dose of IG is needed and then as the viral load decreases the dose can be adjusted downwards. The importance of the appropriate dosing cannot be overstated, especially given that low concentrations for certain anti-viral IGs have been correlated with enhanced disease [22]. The best documented example is that of dengue virus infection. Halstead and colleagues first introduced the concept of antibody-mediated enhancement of dengue infections and showed that, at high dilutions, neutralizing IgG antibodies (as well as undiluted non-neutralizing antibodies) were able to enhance the infection of human and monkey cultured cells [23, 24] and in rhesus monkeys in vivo [25]. Recent studies have shown that individuals with low circulating IG titers have the highest risk for severe dengue disease [26]. Enhancement of infection by antibodies has been observed for coronaviruses that cause severe disease, both in vitro for MERS [27] and SARS [28] and, in vivo in the case of feline encephalitis [29]. A trend for worsening outcomes at low concentrations of mAb CC12.1 was seen in Syrian hamsters challenged with SARS-CoV-2, with the authors hypothesizing the possibility for antibody-mediated enhancement of disease [20]. It remains a matter of considerable controversy whether the phenomenon of antibody-dependent enhancement of SARS-CoV-2 infection can occur in the clinic, given that to date, it has not been reported. There has been no indication of such an enhancement in any of the clinical trials performed so far with convalescent plasma. However, considering the potential for adverse reactions, a high initial (loading) dose and repeat administration of therapeutic IG may be the best strategy for minimizing potential toxicity and maximizing efficacy.

In summary, the concept of matching viral load and dose selection appears to be valid for anti-viral polyclonal IG [13] and $\mathrm{mAbs}$ [20]. Drug-virus interaction is discussed in detail in the context of PK in the next section.

\section{PK and Impact of Drug-Virus Interaction on PK}

Modern-day drug therapy requires a proper understanding of the PK of a product. Pharmacokinetics plays an important role in guiding the dose of a product in a patient population or an individual. An important pharmacokinetic parameter, based on which the dose of a product is generally selected, is exposure or area under the curve (AUC) or a related parameter, the clearance of the product (clearance $=$ dose/AUC). Binding of an IG product to a virus initially leads to lower AUC or higher clearance and a shorter half-life. The following examples highlight the importance of PK and the relationship between viral load and drug exposure or clearance.

\subsection{Example 1}

In a study conducted by Fletcher et al. [30], 12 subjects with acquired immunodeficiency syndrome received hyperimmune anti-human immunodeficiency virus (HIV) IG (HIVIG). HIVIG is an intravenous IG formulated as a $5 \%$ protein solution in normal saline. HIVIG was prepared from HIV-infected asymptomatic donors with a CD4 cell count greater than 400 cells $/ \mathrm{mL}$ and a high titer of antibody to HIV-1 p24 protein. HIVIG was administered intravenously every 28 days; the first two doses were $50 \mathrm{mg} / \mathrm{kg}$ of body weight followed by two doses at $200 \mathrm{mg} / \mathrm{kg}$. For the pharmacokinetic study, anti-p24 antibody was measured based on a frequent blood sampling scheme from $5 \mathrm{~min}$ to 28 days after drug administration. For the pharmacokinetic analysis, the reciprocal titer (RT) of each anti-p24 antibody 
was used. Six subjects had measurable HIV antigens in the serum when they entered into the study. Following the first dose of HIVIG, serum HIV antigens became undetectable and remained so throughout the remainder of the study. The presence of HIV antigens had substantial impact on the PK of HIVIG at both doses. Lower AUC and higher clearance were noted in the subjects who had HIV antigens compared to those subjects who were HIV antigen negative (Table 1). Interestingly, the clearance in the antigen-negative group increased with the higher dose. This is likely due to FcRn saturation. The study indicated that the binding of HIV antigens with HIVIG led to higher clearance and a shorter halflife of HIVIG in subjects with HIV antigens than in subjects without HIV antigens.

\subsection{Example 2}

Dickson et al. [31] conducted a study to assess the impact of lamivudine on hepatitis B antibody (anti-HBs) and dosage requirements of intravenous 5\% hepatitis B IG (HBIG) in the first 36 weeks post-liver transplantation (LT). The theory behind the study was that lamivudine combined with HBIG might prevent post-LT HBV recurrence. Thirty adult subjects $\geq 18$ years of age participated in the study. The study duration was 36 weeks and all patients received lamivudine for 36 weeks. Patients received intravenous HBIG 20,000 IU (about $45 \mathrm{mg} / \mathrm{kg}$ ) on the day of LT, 10,000 on days 1-7 and weeks 4 and 8 , and 5000 every 4 weeks thereafter. Subjects were divided into three groups based on their HBV DNA replicative status. A replicator (R) was defined as HBV DNA $\geq 5 \mathrm{pg} / \mathrm{mL}$ and a non-replicator as $<5 \mathrm{pg} / \mathrm{mL}$. The three groups were defined as follows:

- The Nn group in which patients were non-replicators at the time of lamivudine initiation and at the time of LT (HBV DNA was undetected in this group).

- The Rn group in which patients were replicators at the time of lamivudine initiation but non-replicators at the time of or within 2 weeks prior to LT (HBV DNA was undetected in this group).
- The $\mathrm{Rr}$ group in which patients were replicators at both occasions (HBV DNA pre-LT levels from 11 to $539 \mathrm{pg} /$ $\mathrm{mL}$ in this group).

In this study, PK of HBIG was also evaluated for four periods following LT. These periods were days $1-2$, days $3-7$, days $8-30$, and $>30$ days. The pharmacokinetic parameters of HBIG for three groups are shown in Table 2.

At the beginning of the pharmacokinetic analysis (days $1-2$ ), there was a substantial pharmacokinetic difference as reflected in the higher clearance and shorter half-life in subjects with the actively replicating virus (higher viral load) vs non-replicating subjects (Table 2). The clearance decreased and the half-life increased with time (four periods) from LT for all patient groups. The clearance was $70 \mathrm{~mL} / \mathrm{hour}$ for the $\mathrm{Nn}$ group and $134 \mathrm{~mL} /$ hour for the Rn group in the first period (days 1-2). The clearance and half-life became similar for the Rn and Nn groups at the end of the third period (days 8-30) and by the fourth period (>30 days) the clearance was similar for both these groups ( $7 \mathrm{~mL} /$ hour $)$. A

Table 2 Pharmacokinetic (PK) parameters of hepatitis B immunoglobulin in liver transplantation (LT) adults as a function of hepatitis virus replication status

\begin{tabular}{lllll}
\hline PK parameters & Period (days) & $\mathrm{Nn}$ & $\mathrm{Rn}$ & $\mathrm{Rr}$ \\
\hline Clearance (mL/h) & $1-2$ & 70 & 134 & 3260 \\
& $3-7$ & 46 & 64 & 450 \\
& $8-30$ & 14 & 14 & 24 \\
& $>30$ & 7 & 7 & 13 \\
Half-life (h) & $1-2$ & 59 & 27 & 0.7 \\
& $3-7$ & 84 & 57 & 5 \\
& $8-30$ & 266 & 270 & 123 \\
& $>30$ & 446 & 545 & 204 \\
\hline
\end{tabular}

The Nn group in which patients were non-replicators at the time of lamivudine initiation and at the time of LT

The Rn group in which patients were replicators at the time of lamivudine initiation but non-replicators at the time of or within 2 weeks prior to LT

The $\mathrm{Rr}$ group in which patients were replicators at both occasions
Table 1 Pharmacokinetic parameters of human immunodeficiency virus (HIV) hyperimmune immunoglobulin in adults as a function of the HIV antigen

\begin{tabular}{|c|c|c|c|c|c|}
\hline $\begin{array}{l}\text { Dose and HIV } \\
\text { virus status }\end{array}$ & Peak (RT) & Trough (RT) & AUC (RT*days) & $\begin{array}{l}\text { Clearance } \\
\text { (mL/kg/day) }\end{array}$ & Half-life (days) \\
\hline \multicolumn{6}{|l|}{$50 \mathrm{mg} / \mathrm{kg}$} \\
\hline Antigen+ & $5940(61)$ & $863(22)$ & $67,684(40)$ & $4.2(29)$ & $15.3(17)$ \\
\hline Antigen- & $9980(38)$ & $2022(29)$ & $137,794(28)$ & $1.9(41)$ & $27.2(37)$ \\
\hline \multicolumn{6}{|l|}{$200 \mathrm{mg} / \mathrm{kg}$} \\
\hline Antigen+ & $24,600(43)$ & $3298(28)$ & $271,949(23)$ & $4.1(32)$ & $17.7(22)$ \\
\hline Antigen- & $34,824(44)$ & $5557(47)$ & $440,880(49)$ & $3.2(49)$ & $20.2(31)$ \\
\hline
\end{tabular}

$A U C$ area under the curve, $R T$ reciprocal titer; peak titer vales are concentrations of the anti-p24 antibody at 5 minutes after the end of infusion and the trough values are at day 28 before the next dose 
similar pattern was noted with the half-life. However, the clearance for the $\mathrm{Rr}$ group was $3260 \mathrm{~mL} / \mathrm{hour}$ in the first period and then decreased substantially with time and by the fourth period clearance was $13 \mathrm{~mL} / \mathrm{min}$. The high clearance in the $\mathrm{Rr}$ group was likely owing to the presence of HBV DNA and its binding to HBIG compared to the other two groups. Overall, by the fourth period, the clearance decreased and the half-life increased substantially compared with the first period in all four groups.

Overall, the pharmacokinetic analysis indicates that IG clearance is very high in patients with the replicating virus (higher viral load) as compared with subjects with a minimal viral load. The results support targeting a hyperimmune IG treatment strategy at an early stage of viral infection to match the viral load.

\subsection{Example 3}

McGory et al. [13] conducted a clinical trial to evaluate the effectiveness of HBIG (HepaGam B) in the prevention of HBV recurrence following LT. This was a multi-center openlabel study involving HBsAg-positive and $\mathrm{HBeAg}$-negative LT patients. There were 27 LT patients who received HBIG. In this study, the authors also conducted a pharmacokinetic analysis of anti-HBs. The pharmacokinetic study was grouped by time from LT, pre-transplant (period 0), days 0-2 (period 1), days 3-7 (period 2), days 8-30 (period 3), days 31-90 (period 4), and $>90$ days (period 5).

The PK of anti-HBs in patients who had successful transplantations (no recurrence) followed a pattern over time. Over time, the clearance decreased, and the half-life increased and became stable after 3 months. Before transplantation, the clearance was $77.4 \pm 87.5 \mathrm{~L} / \mathrm{day} / \mathrm{kg}$ and the half-life was $0.8 \pm 0.5$ days. After transplantation, the clearance decreased from 13.5 L/day/kg (period 1) to $0.002 \mathrm{~L} /$ day $/ \mathrm{kg}$ (period 5), and the half-life increased from 0.7 days (period 1) to 14.1 days (period 5). In periods 1 and 2, the elimination of anti-HBs was significantly greater in $\mathrm{HBeAg}$ positive patients compared with $\mathrm{HBeAg}$-negative subjects; $\mathrm{HBeAg}+$ being a marker of viral replication and correlated with higher viral load. This difference in clearance and half-life between the two groups disappeared 1 week after transplantation and was indistinguishable in periods 3,4 , and 5 but this difference did not alter the clinical treatment regimens (the reason for not changing the dose was not mentioned). This change in clearance and half-life of anti-HBs can be attributed to their binding to the virus and clearance in proportion to the viral load. The authors indicated that anti-HB titers (trough concentrations) required to minimize the risk of hepatitis B were $>500 \mathrm{IU} / \mathrm{L}$ for days $0-7,>250$ IU/L for days 8-90, and $>100$ IU/L. This time-dependent change in the protective levels of anti-HBs suggests that it is

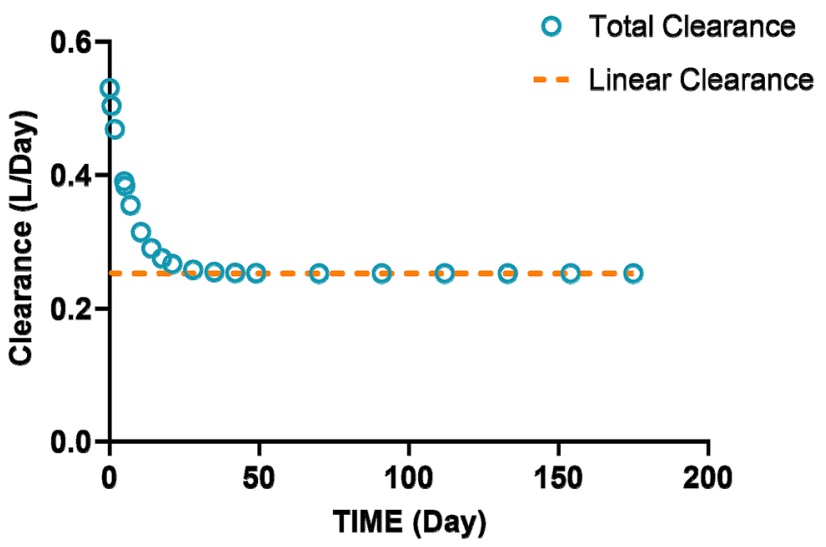

Fig. 1 Total and nonspecific linear clearance vs time for rituximab in a typical patient with no disease progression. The target-mediated disposition of rituximab was modeled as nonlinear clearance as previously described by Rozman et al. [32] in patients with diffuse large B-cell lymphoma. Total clearance is the sum of both linear and nonlinear clearance

possible to adjust the dose that can reduce the safety concern and also be cost effective. This example again emphasizes the need for matching the dose of hyperimmune IG to the viral load.

In a clinical setting, it is not easy to conduct a pharmacokinetic study in an individual patient owing to the need to withdraw multiple samples, but it is possible to conduct pharmacokinetic studies during drug development. The pharmacokinetic study can provide a mean dose for a given population and if possible, a concentration-viral load relationship. This relationship can then be used to individualize the dose of a product. In a clinical setting, one can take a blood sample before and after dosing the product and a later sample can be taken at an appropriate time to monitor the drug effect as well as the viral load and adjust the dose if needed.

\subsection{Example 4}

The examples presented above were in patients with HIV and HBV infections, which are associated with viremia. Pharmacokinetic data of patients with viral infections not associated with viremia are not readily available in the published literature. Instead, we found examples of patients with tumors receiving mAbs. We suggest that the treatment of tumor cells in tissues with antibodies is analogous to treatment of virus in tissues. In both cases, the relevant antigen is present and targeted by an antibody that may attack the virus or the cell. The antibody/antigen complex is cleared by the reticuloendothelial system.

One such example involves treatment of lymphoma with the mAb, rituximab, directed at the B-cell antigen, CD20. Patients with lymphoma received rituximab and blood 
Table 3 Potential dosing approaches for anti-SARS-CoV-2 immunoglobulin

\begin{tabular}{|c|c|c|}
\hline & $\begin{array}{l}\text { Pre- or post-exposure before/ } \\
\text { early-stage infection in high-risk } \\
\text { subjects }\end{array}$ & Severe infection \\
\hline Viral load level & Minimal & High \\
\hline $\begin{array}{l}\text { Predicted impact of viral loads on PK (COVID-19 } \\
\text { vs healthy subjects) }\end{array}$ & Minimal to no change in PK & Increased clearance and short half-life \\
\hline $\begin{array}{l}\text { Dosing strategy without pharmacokinetic monitor- } \\
\text { ing }\end{array}$ & Single low dose (e.g., $100 \mathrm{mg} / \mathrm{kg}^{\mathrm{b}}$ ) & $\begin{array}{l}\text { Single relatively higher dose (e.g., } \geq 400 \mathrm{mg} / \mathrm{kg}^{\mathrm{c}} \text { ), or } \\
\text { Multiple dose (e.g., } 100 \mathrm{mg} / \mathrm{kg} \text { ) guided by pharma- } \\
\text { cokinetic monitoring (see below) }\end{array}$ \\
\hline Dosing strategy with pharmacokinetic monitoring & Not applicable & $\begin{array}{l}\text { Frequent monitoring of serum antibody levels (e.g., } \\
\text { pre- and post-dose on days } 1,3,5,7,14 \text {, and } 28) \\
\text { Repeat dosing if antibody levels rapidly decline } \\
\text { within } 1-5 \text { days after initial dosing }\left(\text { e.g., } C_{\text {dayl }} /\right. \\
C_{\text {day5 }}>2 \text { ) }\end{array}$ \\
\hline
\end{tabular}

FDA US Food and Drug Administration, $I G$ immunoglobulin, $P K$ pharmacokinetics

${ }^{a}$ Currently, the impact of viral loads on the PK of antibody therapy in patients with COVID-19 patients is unknown but predicted based on prior experience with other diseases (see examples $1-4$ in the text)

${ }^{\mathrm{b}, \mathrm{c}}$ Suggested doses of 100 or $400 \mathrm{mg} / \mathrm{kg}$ are estimates based on the experience with FDA-approved IG products. The actual dose would depend on the anti-SARS-CoV2 neutralization titers of the preparation under development

samples were taken to assess pharmacokinetic parameters [32]. Initially, the clearance of the antibody was very rapid and nonlinear $(0.53 \mathrm{~L} /$ day $)$ but decreased by half $(0.25 \mathrm{~L} /$ day) after repeated dosing and when the trough concentrations reached a plateau (Fig. 1). This can be explained by the high initial tumor load leading to target-mediated drug disposition that initially resulted in more rapid elimination of the antibody. As the tumor load decreased, the antibody was cleared less rapidly, and could maintain a stable trough concentration when given less frequently. A similar targetmediated drug disposition phenomenon was observed for daratumumab in patients with multiple myeloma. The pharmacokinetic finding show that initial treatment with daratumumab required frequent dosing to achieve trough concentrations that were associated with clinical improvement [33]. Based on these findings, the recommended dose for daratumumab in patients with multiple myeloma is $16 \mathrm{mg} /$ $\mathrm{kg}$ weekly for 8 weeks, followed by $16 \mathrm{mg} / \mathrm{kg}$ every 2 weeks for 16 weeks, and every 4 weeks thereafter [33].

What is striking is the similarity between the dosing recommendations for daratumumab in patients with multiple myeloma and for HBIG in patients with post-transplant $\mathrm{HBV}+$. In both cases, more frequent dosing was required initially to control the tumor and virus, respectively. It is likely that, initially in both cases, a high antigenic load led to rapid clearance of the antibodies.

\section{Suggestions on Dosing Strategy for COVID-19}

The above examples are instructive in designing a dosing strategy of antibody products for patients with COVID-19. SARSCOV-2 has been found in the nasopharynx, lungs, and stools. The total body viral load is not known but is probably high in hospitalized patients with moderate and severe infections. Preand post-exposure therapy in mild cases may be amenable to single doses of polyclonal antibody or mAb administration in individuals at high risk because of age, underlying diseases, or first responders. However, moderate or severe cases with high viral loads may require a different dosing strategy (Table 3). Dosing with high-titer polyclonal antibodies or mAbs should be monitored by sampling serum levels in the first few days to see if antibodies are present or being cleared rapidly (Table 3 ). Rapid clearance will indicate that the virus load is high and that repeated doses are needed. This should be continued until antibody levels plateau, signaling that the virus is under control and that the frequency of dosing can be reduced. Thus, even in the absence of accurate viral load levels, it may be possible to adjust antibody doses based on rates of antibody clearance, as the latter likely correlates with viral load. This is only feasible in patients with relatively early disease before they develop endogenous antibody responses.

As an alternative approach to initial frequent dosing, one may consider starting with a relatively higher dose. However, doses exceeding $400 \mathrm{mg} / \mathrm{kg}$ may saturate the FcRn recycling receptor, and independently of the virus lead to increased clearance [34]. Thus, it will likely be more efficient and more 
effective to use lower doses more frequently than a single high dose.

\section{Conclusions}

Overall, study design and dose selection for antiviral antibody products require special consideration of viral load, antibody-virus interaction, and PK of the antibody. Preclinical studies can help determine the first-in-human dose regimen based on the relationship between antibody dose and viral load. Timing of antibody administration is critical, in that the antibody is more likely to be effective given early in the course of the disease when the viral load is relatively low. The initial dose regimen for an antibody product should be sufficiently high to compensate for the rapid clearance as a result of a high viral load. Later, as the rate of drug clearance is decreased because of elimination of the virus, the dose can be lowered. Dose adjustment based on pharmacokinetic monitoring is critical to achieve an optimal treatment effect.

\section{Declarations}

Conflict of interest The authors have no conflicts of interest to declare.

Funding In-house funding from the U.S. FDA.

Ethical approval No financial conflicts of interest, all the data are in the public domain.

Consent for publication FDA management consented to this publication.

Availability of data and materials All available in references and product Package Inserts.

Code availability Non-applicable.

Open Access This article is licensed under a Creative Commons Attribution-NonCommercial 4.0 International License, which permits any non-commercial use, sharing, adaptation, distribution and reproduction in any medium or format, as long as you give appropriate credit to the original author(s) and the source, provide a link to the Creative Commons licence, and indicate if changes were made. The images or other third party material in this article are included in the article's Creative Commons licence, unless indicated otherwise in a credit line to the material. If material is not included in the article's Creative Commons licence and your intended use is not permitted by statutory regulation or exceeds the permitted use, you will need to obtain permission directly from the copyright holder. To view a copy of this licence, visit http://creativecommons.org/licenses/by-nc/4.0/.

\section{References}

1. CDC. COVID-19 pandemic planning scenarios. https://www. cdc.gov/coronavirus/2019-ncov/hcp/planning-scenarios.html. Accessed 25 Aug 2020.

2. Mayo Clinic. Coronavirus disease 2019 (COVID-19). https:// www.mayoclinic.org/diseases-conditions/coronavirus/symptomscauses/syc-20479963. Accessed 15 July 2020.

3. Wiersinga WJ, Rhodes A, Cheng AC, Peacock SJ, Prescott HC. Pathophysiology, transmission, diagnosis, and treatment of coronavirus disease 2019 (COVID-19): a review. JAMA. 2020;324(8):782-93.

4. NIH. Potential antiviral drugs under evaluation for the treatment of COVID-19. https://www.covid19treatmentguidelines.nih.gov/ antiviral-therapy/. Accessed 25 Aug 2020.

5. US FDA. FDA issues emergency use authorization for convalescent plasma as potential promising COVID-19 treatment, another achievement in administration's fight against pandemic. https:// www.fda.gov/news-events/press-announcements/fda-issues-emerg ency-use-authorization-convalescent-plasma-potential-promisingcovid-19-treatment. Accessed 28 Aug 2020.

6. NIH. Immunomodulators under evaluation for the treatment of COVID-19. https://www.covid19treatmentguidelines.nih.gov/ immune-based-therapy/immunomodulators/. Accessed 25 Aug 2020.

7. Pujadas E, Chaudhry F, McBride R, Richter F, Zhao S, Wajnberg A, et al. SARS-CoV-2 viral load predicts COVID-19 mortality. Lancet Respir Med. 2020;38(5):661-71.e2.

8. Zou L, Ruan F, Huang M, Liang L, Huang H, Hong Z, et al. SARS-CoV-2 viral load in upper respiratory specimens of infected patients. N Engl J Med. 2020;382(12):1177-9.

9. Zheng S, Fan J, Yu F, Feng B, Lou B, Zou Q, et al. Viral load dynamics and disease severity in patients infected with SARSCoV-2 in Zhejiang province, China, January-March 2020: retrospective cohort study. BMJ. 2020;21(369):m1443.

10. Wang Y, Zhang L, Sang L, Ye F, Ruan S, Zhong B, et al. Kinetics of viral load and antibody response in relation to COVID-19 severity. J Clin Investig. 2020;130(10):5235-44.

11. Westblade LF, Brar G, Pinheiro LC, Paidoussis D, Rajan M, Martin P, et al. SARS-CoV-2 viral load predicts mortality in patients with and without cancer who are hospitalized with COVID-19. Cancer Cell. 2020;38(5):661-71.e2.

12. Levy G. Pharmacologic target-mediated drug disposition. Clin Pharmacol Ther. 1994;56(3):248-52.

13. McGory RW, Ishitani MB, Oliveira WM, Stevenson WC, McCullough CS, Dickson RC, et al. Improved outcome of orthotopic liver transplantation for chronic hepatitis B cirrhosis with aggressive passive immunization. Transplantation. 1996;61(9):1358-64.

14. US FDA. Anthrasil. https://www.fda.gov/vaccines-blood-biolo gics/approved-blood-products/anthrasil. Accessed 21 Aug 2020.

15. Greig SL. Obiltoxaximab: first global approval. Drugs. 2016;76(7):823-30.

16. Zhou C, Lehar S, Gutierrez J, Rosenberger CM, Ljumanovic $\mathrm{N}$, Dinoso J, et al. Pharmacokinetics and pharmacodynamics of DSTA4637A: a novel THIOMAB antibody antibiotic conjugate against Staphylococcus aureus in mice. MAbs. 2016;8(8):1612-9.

17. Subramanian KN, Weisman LE, Rhodes T, Ariagno R, Sanchez PJ, Steichen J, et al. Safety, tolerance and pharmacokinetics of a humanized monoclonal antibody to respiratory syncytial virus in premature infants and infants with bronchopulmonary dysplasia. MEDI-493 Study Group. Pediatr Infect Dis J. 1998;17(2):110-5. 
18. US FDA. FDA package insert: Synagis (palivizumab). https:// www.accessdata.fda.gov/drugsatfda_docs/label/2014/103770s518 5lbl.pdf. Accessed 21 Aug 2020.

19. medRxiv. Effect of convalescent plasma on mortality among hospitalized patients with COVID-19: initial three-month experience. https://www.medrxiv.org/content/10.1101/2020.08.12.20169 $359 v 1$. Accessed 25 Aug 2020.

20. Rogers TF, Zhao F, Huang D, Beutler N, Burns A, He WT, et al. Isolation of potent SARS-CoV-2 neutralizing antibodies and protection from disease in a small animal model. Science. 2020;369(6506):956-63.

21. Hassan AO, Case JB, Winkler ES, Thackray LB, Kafai NM, Bailey $\mathrm{AL}$, et al. A SARS-CoV-2 infection model in mice demonstrates protection by neutralizing antibodies. Cell. 2020;182(3):744-53. e4.

22. Porterfield JS. Antibody-dependent enhancement of viral infectivity. Adv Virus Res. 1986;31:335-55.

23. Halstead SB, O'Rourke EJ. Antibody-enhanced dengue virus infection in primate leukocytes. Nature. 1977;265(5596):739-41.

24. Halstead SB, O'Rourke EJ, Allison AC. Dengue viruses and mononuclear phagocytes. II. Identity of blood and tissue leukocytes supporting in vitro infection. J Exp Med. 1977;146(1):218-29.

25. Halstead SB. In vivo enhancement of dengue virus infection in rhesus monkeys by passively transferred antibody. J Infect Dis. 1979;140(4):527-33.

26. Katzelnick LC, Gresh L, Halloran ME, Mercado JC, Kuan G, Gordon A, et al. Antibody-dependent enhancement of severe dengue disease in humans. Science. 2017;358(6365):929-32.

27. Wan Y, Shang J, Sun S, Tai W, Chen J, Geng Q, et al. Molecular mechanism for antibody-dependent enhancement of coronavirus entry. J Virol. 2020;94(5):e02015-e2019.
28. Wang SF, Tseng SP, Yen CH, Yang JY, Tsao CH, Shen CW, et al. Antibody-dependent SARS coronavirus infection is mediated by antibodies against spike proteins. Biochem Biophys Res Commun. 2014:451(2):208-14.

29. Weiss RC, Scott FW. Antibody-mediated enhancement of disease in feline infectious peritonitis: comparisons with dengue hemorrhagic fever. Comp Immunol Microbiol Infect Dis. 1981;4(2):175-89.

30. Fletcher CV, Goodroad BK, Cummins LM, Henry K, Balfour HH Jr, Rhame FS. Pharmacokinetics of hyperimmune anti-human immunodeficiency virus immunoglobulin in persons with AIDS. Antimicrob Agents Chemother. 1997;41(7):1571-4.

31. Dickson RC, Terrault NA, Ishitani M, Reddy KR, Sheiner P, Luketic $\mathrm{V}$, et al. Protective antibody levels and dose requirements for IV 5\% Nabi Hepatitis B immune globulin combined with lamivudine in liver transplantation for hepatitis B-induced end stage liver disease. Liver Transpl. 2006;12(1):124-33.

32. Rozman S, Grabnar I, Novakovic S, Mrhar A, Jezersek NB. Population pharmacokinetics of rituximab in patients with diffuse large B-cell lymphoma and association with clinical outcome. Br J Clin Pharmacol. 2017;83(8):1782-90.

33. Xu XS, Yan X, Puchalski T, Lonial S, Lokhorst HM, Voorhees $\mathrm{PM}$, et al. Clinical implications of complex pharmacokinetics for daratumumab dose regimen in patients with relapsed/refractory multiple myeloma. Clin Pharmacol Ther. 2017;101(6):721-4.

34. Mahmood I, Tegenge MA, Golding B. Considerations for optimizing dosing of immunoglobulins based on pharmacokinetic evidence. Antibodies (Basel). 2020;9(2):24. 